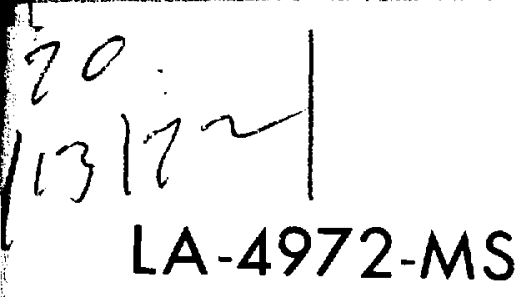

AN INFORMAL REPORT

\title{
Charge-Sensitive Preamplifier for Use with Large Proportional Counter Arrays
}


This report was prepared as an account of work sponsored by the United States Government. Neither the United States nor the United States Atomic Energy Commission, nor any of their employees, nor any of their contractors, subcontractors, or their employees, makes any warranty, express or implied, or assumes any legal liability or responsibility for the accuracy, completeness or usefulness of any information, apparatus, product or process disclosed, or represents that its use would not infringe privately owned rights.

In the interest of prompt distribution, this LAMS report was not edited by the Technical Information staff.

Printed in the United States of America. Available from

National Technical Information Service

U. S. Department of Commerce

5285 Port Royal Road

Springfield, Virginia 22151

Price: Printed Copy \$3.00; Microfiche $\$ 0.95$ 


\title{
LA-4972-MS
}

An Informal Report

UC-15 and UC-37

ISSUED: June 1972

\section{los Dalomos}

\section{scientific laboratory}

of the University of California

LOS ALAMOS, NEW MEXICO 87544

1

\section{Charge-Sensitive Preamplifier for Use with Large Proportional Counter Arrays*}

by

\author{
Larry V. East
}

James E. Swanson

This report NOTICE

sponsored by was prepared as an account of work

sponsored by the United States Governinent. Neither

the United States nor the United States Atomic Energy

Commission, nor any of their employees, nor any of

their contractors, subcontractors, or their er any of

makes any warranty, express or implied, or assployees,

legal linbility or responsibility for the or assumes any

pleteness of usefulness of any for the accuracy, com-

product or process disclosed information, apparatus,

would not infringe privately, or represents that its use

"Work supported by Division of Nuclear Materials Security, AEC. 


\title{
CHARGE-SENSITIVE PREAMPLIFIER FOR USE \\ WITH LARGE PROPORTIONAL COUNTER ARRAYS
}

\author{
by
}

Larry V. East and James E. Swansen

\begin{abstract}
ABSTRAC'T
A charge-sensitive preamplifier developed for use with large arrays of proporitional counters is described. Pos itive feedback is utiiized to essentially eliminate charge seirsitivity dependence upon input capacity. The preamplifier operates from a single $+12 \mathrm{~V}$ power source, and its output is linear to a'sout $4 \mathrm{~V}$ when operated into a $100-\mathrm{ohm}$ load.
\end{abstract}

\section{INTROLUCTION}

A charge-sensitive, or integrating, preamplifier designed for use with large arrays of proportional courters is described in this report. Its characteristics are as follows:

a) Maximum output pulse amplitude, for negative input signals, is $\sim 8 \mathrm{~V}$ (positive) unterminated, or $\sim 4 \mathrm{~V}$ into $100 \Omega$.

b) Switch selectable charge sensitivity of $4.5 \times 10^{5} \mathrm{~V} / \mu \mathrm{coul}$ or $2.8 \times 10^{6} \mathrm{~V} / \mu \mathrm{coul}$ into a 100 is load.

c) The charge sensitivity is essentially independent of input capacity up to at least $5000 \mathrm{pF}$.

d) Input protected from high voltage transients.

e) Output pulse decay time variable from

$0.5 \mu \mathrm{s}$ to $50 \mu \mathrm{s}$ by means of small plug-in pulse shaping networks.

f) The preamplifier operates from a single $+12 \mathrm{~V}$ power source.
Although the preamplifier was designed for use with neutron detectors consisting of large proportional counter arrays ${ }^{(1,2)}$, it should prove useful in other counter applications involving high input capacitance.

\section{C IRCUIT DESCRIPTION}

A schematic diagram of the preamplifier is shown in Fig. 1. The charge sensitive input loop consists of $Q_{1}-Q_{5}$. A $2 N 4860$ FET was chosen for $Q_{1}$ because of its very high $g_{m}$ (typically 20-30 $\mathrm{ma} / \mathrm{V}$ ) in order to reduce the effect of input capacity on the preamplifier noise output. $Q_{2}$ is a constant current source for $Q_{1} \cdot Q_{4}$ is a grounded base amplifier forming the upper half of a cascade amplifier with $Q_{1}$, with additional current gain provided by $Q_{3}$. Charge feedback is accomplished by means of the $2.2 \mathrm{pF}$ capacitor, $\mathrm{C}_{2}$, from the emitter of $Q_{5}$ to the gate of $Q_{1}$. The 20M resistor. $\mathrm{R}_{2}$, shunting $\mathrm{C}_{2}$ results in a pulse decay time of $\sim 50 \mu \mathrm{s}$. Diodes $D_{1}$ and $D_{2}$ protect $Q_{1}$ from large 


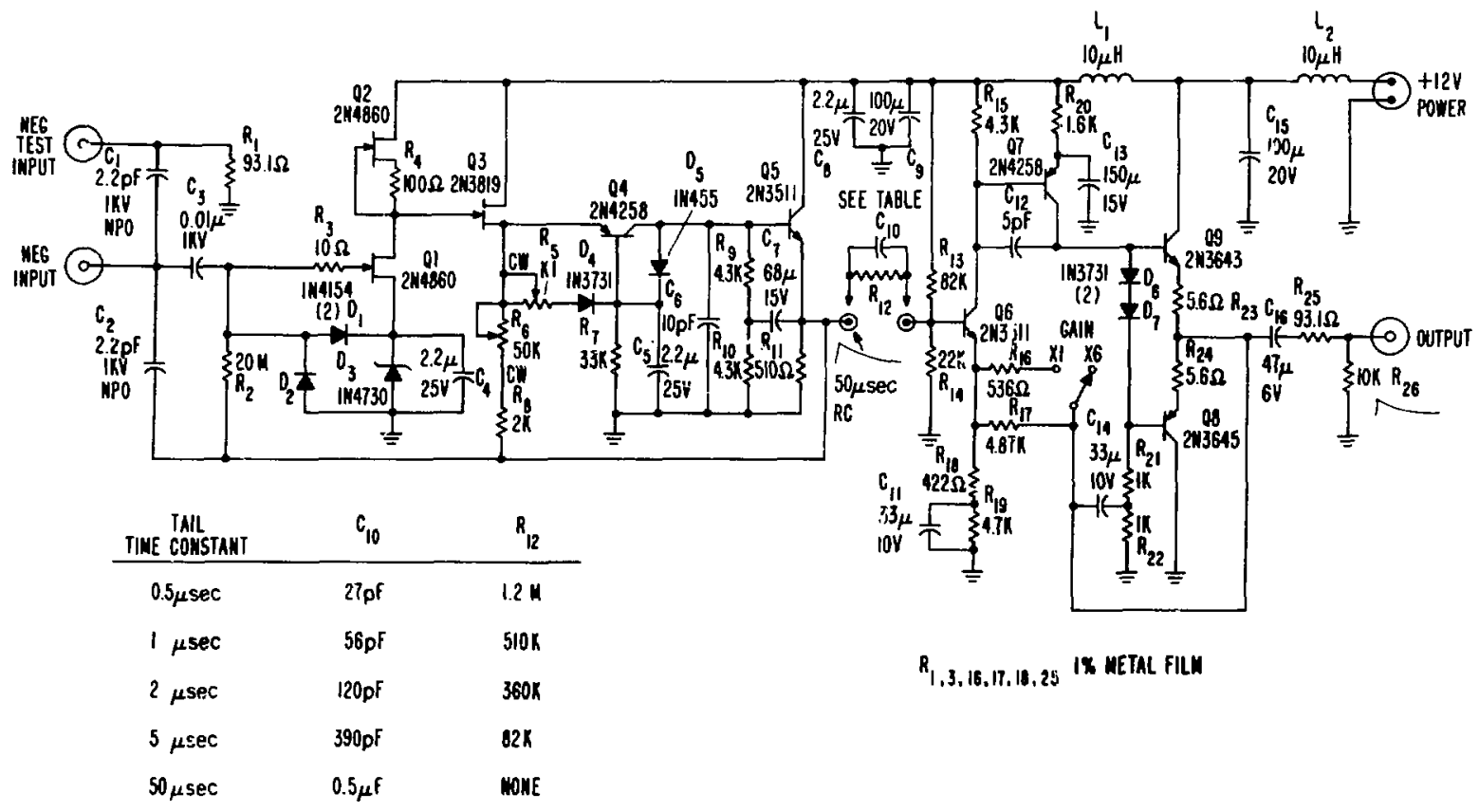

Fig. 1. Preamplifier schematic diagram.

voltage transients that may occur when detector $u$ tas is suddenly applied or removed from the preamplifier input.

It is desirable to makt the open-loop gain of the charge sensitive amplifier stage large in order to reduce the dependence of charge sensitivity on input capacity. As may be easily shown ${ }^{(3)}$, the output, $V_{o}$, resuliting from a charge $Q$ at the input of a charge sensitive amplifier is given by

$$
V_{0}=-\left\{Q / C_{f}\right)\left[A /\left(1+A+C_{i} / C_{f}\right]\right.
$$

where

$$
\begin{aligned}
& A=\text { open-loop midband amplifier gain, } \\
& C_{f}=\text { feedback capacitance, } \\
& C_{i}=\text { input capacitance. }
\end{aligned}
$$

For $A \gg\left(1+C_{i} / C_{f}\right)$, Eq. (1) becomes

$$
\mathrm{V}_{\mathrm{o}} \simeq-\mathrm{Q} / \mathrm{C}_{\mathrm{f}}
$$

hence for large open-loop ga in the charge sensitivity is essentially independent of input capacity. Three techniques have been used in the present design to increase the open-loop gain: 1) $Q_{3}$ provides additional gain between $Q_{1}$ and $Q_{4}, 2$ ) the output of the emitter follower $Q_{5}$ is bootstrapped back to the collector load of $Q_{4}$, and 3) positive feedback $^{(4,5)}$ is applied to the emitter of $Q_{4}$ via $R_{6}$ and $R_{8}$ from the emitter of $Q_{5}$. With the proper adjustment of $R_{6}$, the open-loop gain can be made to approach infinity. A further increase in the positive feedback will result in the amplifier appearing to operate into a negative impedance, and the charge sensitivity will increase rather than decrease with increasing input capacity. $R_{6}$ should be adjusted so that the output pulse height changes less than $5 \%$ for a given input charge when the input capacity is increased from 0 to $\sim 2000 \mathrm{pF}$. An increase in pulse height with input capacity should be avoided, since with too much positive feedback the preamplifier may become unstable for certain combinations of input capacity and shunt resistance. $R_{5}$ is used to set the operating point of the input loop: it should normally be adjusted to produce the fastest output pulse rise-time at the emitter of $Q_{5}$ under conditions of high input capacity $(1000 \mathrm{pF}$ or greater $)$. 


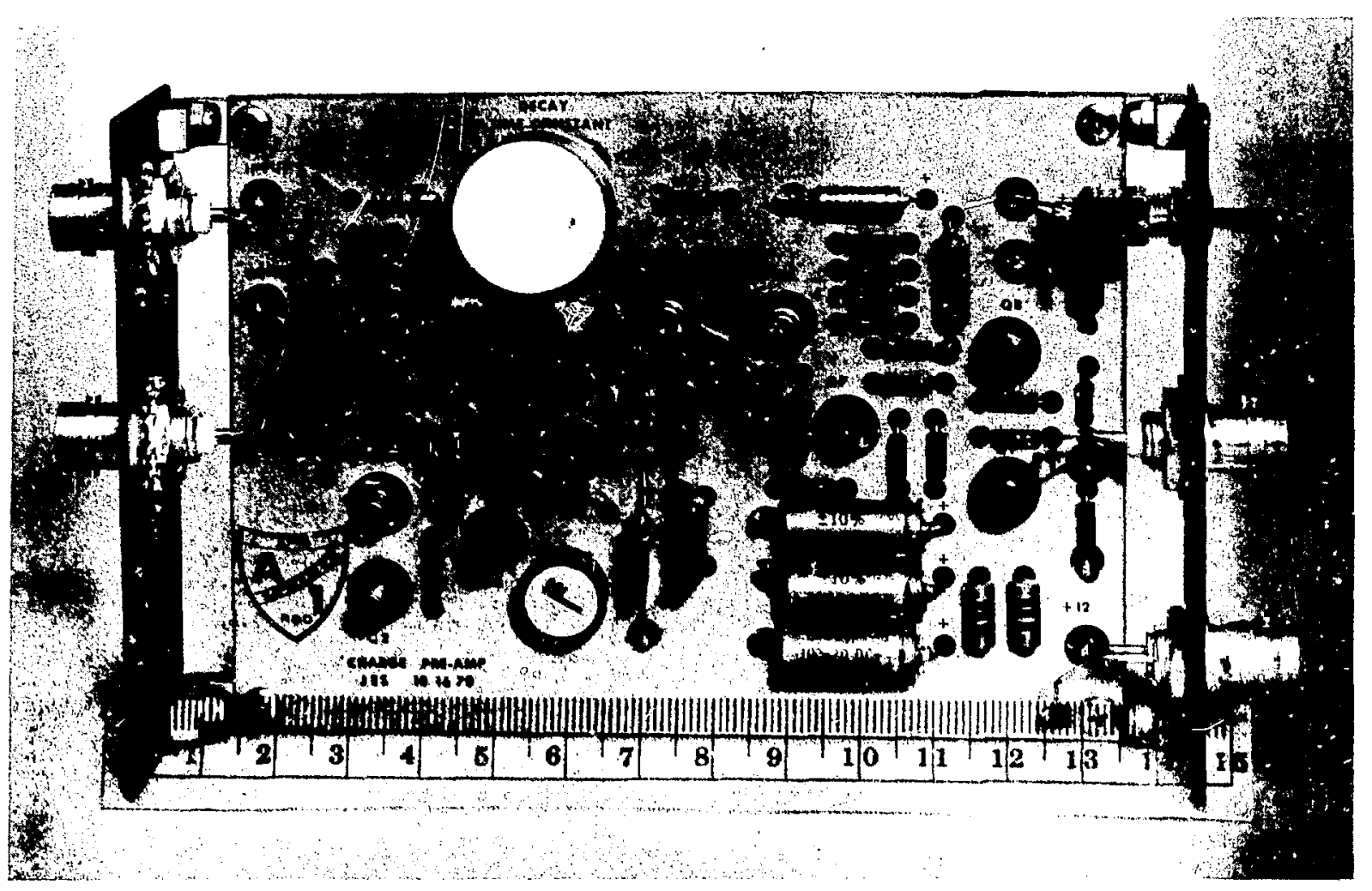

Fig. 2. Top view of completed preamplifier.

Transistors $Q_{6}-Q_{9}$ comprise the output amplifier, which is a feedback stabilized noninverting amplifier of standard design. The output is linear to $>7 \mathrm{~V}$ into an open load, or $\sim 4 \mathrm{~V}$ into a $100 \Omega$ load for positive output pulses (negative preamplifier input). The output will saturate at about $1.5 \mathrm{~V}$ for negative output pulses. Signal coupling to the output stage is through a pole-zero compensation network consisting of $\mathrm{C}_{10}$ and $\mathrm{R}_{12}$. Any output pulse decay time in the range of about $0.5 \mu \mathrm{s}$ to $50 \mu \mathrm{s}$ can be obtained by changing the values of $\mathrm{C}_{10}$ and $\mathrm{R}_{12}$; values for several decay times are given in Fig. 1. The output pulse risetime obtainable from the preamplifier will depend upon the input capacitance, increasing from $<0.1$ $\mu \mathrm{s}$ for no external input capacity to about $0.5 \mathrm{\mu s}$ for $1500 \mathrm{pF}$ input capacity.

\section{PREAMPLIFIER CONSTRUCTION}

The preamplifier is constructed on a 5 in. $x 311 / 16$ in. printed circuit board and housed in a 6 in. $\times 4$ in. $\times 13 / 4$ in. aluminum box. A photograph of the preamplifier is shown in Fig. 2; conponents are identified in Fig. 3. The interstage coupling network is contained in a potted plug-in module, shown in the upper part of Fig. 2. Each module contains three coupling networks, connected between pairs of protruding pins, so that any one of three output pulse decay times may be selected by char.ging the position of the module in the socket mounted on the circuit board. A complete parts list is given in the Appendix. 


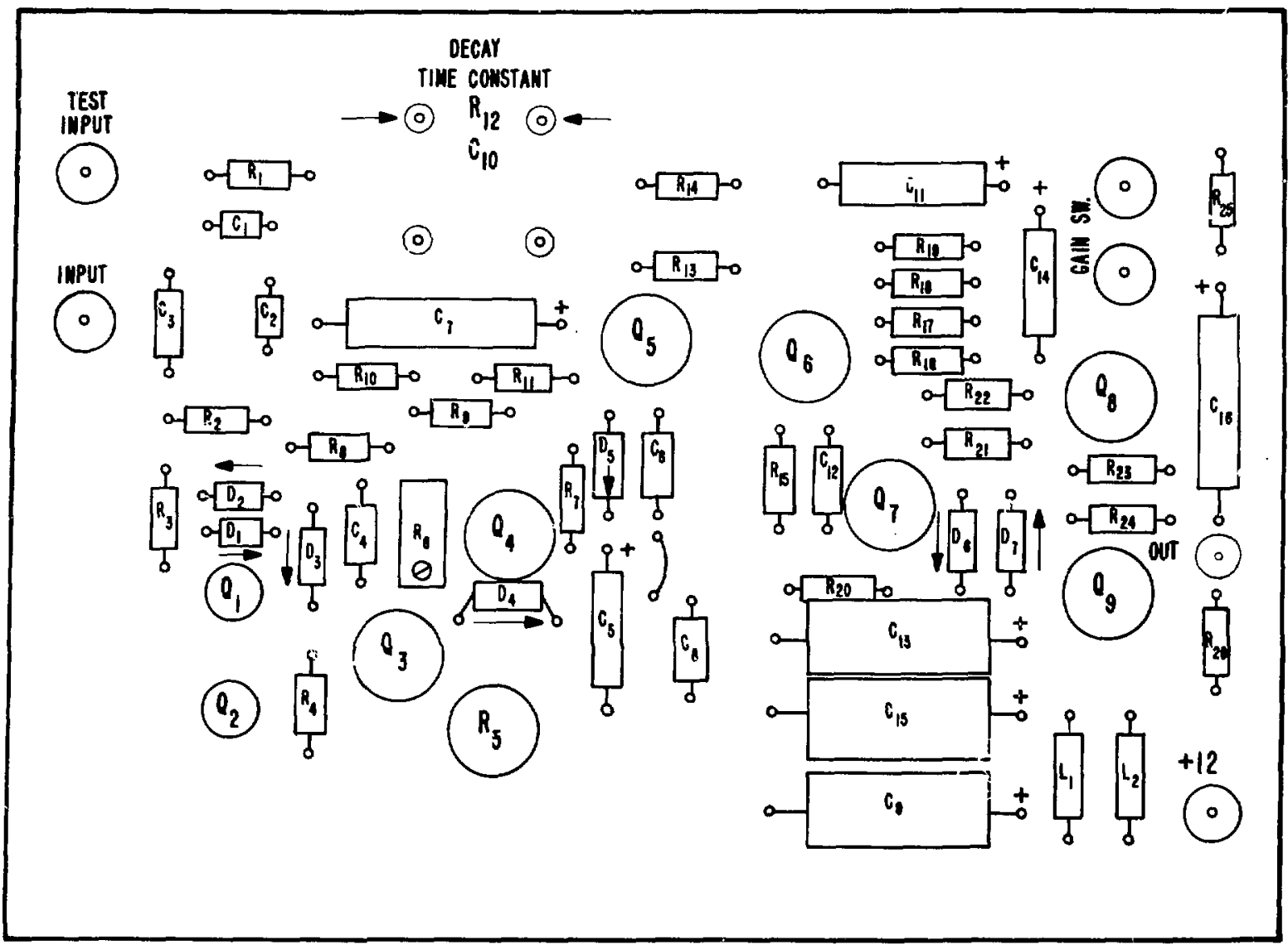

Fig. 3. Component layout. Refer to Fig. 1 or the Appendix for component values.

\section{REFERENCES}

1. L. V. East and R. B. Walton, "Polyethylene Moderated ${ }^{3} \mathrm{He}$ Neutron Detectors". Nucl. Instr. and Meth. 72, 161 (1969).

2. J. E. Foley, "Neutron Coincidence Counters for Nuclear Safeguards Applications", IEEE Trans. Nucl. Sci. (to be published).
3. See, for example, R. L. Chase, Nuclear Pulse Spectrometry (McGraw-Hill, New York, 1961) Ch. 2.

4. W. W. Goldsworthy, Nucl. Instr. and Meth. 52, 343 (1967).

5. J. Hahn and R. Mayer, IRE Trans. Nucl. Sci. NS-9, No. 4, 20 (1962). 
Circuit

Reference

$$
\mathrm{C}_{1}, \mathrm{C}_{2}
$$

$\mathrm{C}_{3}$

$\mathrm{C}_{4}, \mathrm{C}_{5}, \mathrm{C}_{8}$

$\mathrm{C}_{6}$

$\mathrm{C}_{7}$

$\mathrm{C}_{9}, \mathrm{C}_{15}$

$\mathrm{C}_{10}$

$\mathrm{C}_{11}, \mathrm{C}_{14}$

$\mathrm{C}_{12}$

$\mathrm{C}_{13}$

$\mathrm{C}_{16}$

$\mathrm{D}_{1}, \mathrm{D}_{2}$

$D_{3}$

$\mathrm{D}_{4}, \mathrm{D}_{6}, \mathrm{D}_{7}$

$\mathrm{D}_{5}$

$L_{1}, L_{2}$

$Q_{1}, Q_{2}$

$\mathrm{Q}_{3}$

$\mathrm{Q}_{4}, \mathrm{Q}_{7}$

$Q_{5}, Q_{6}$

$Q_{8}$

$\mathrm{Q}_{9}$

$R_{1}, R_{25}$

$\mathrm{R}_{2}$

$\mathrm{R}_{3}$

$\mathrm{R}_{4}$

$R_{5}$

$\mathrm{R}_{6}$

$\mathrm{R}_{7}$

$\mathrm{R}_{8}$

$\mathrm{R}_{\mathrm{g}}, \mathrm{R}_{10^{\prime}} \mathrm{R}_{15}$

$\mathrm{R}_{11}$

$\mathrm{R}_{12}$

$\mathrm{R}_{13}$

$\mathrm{R}_{14}$

$R_{16}$

$\mathrm{R}_{17}$
Description

Capacitor, ceramic disc, NPO, $2.2 \mathrm{pF}, 1 \mathrm{kV}$.

Capacitor, ceramic disc, .01 $\mu \mathrm{F}, 1 \mathrm{kV}$.

Capacitor, ceramic, $2.2 \mu \mathrm{F}, 25 \mathrm{~V}$.

Capacitor, silvered mica, $10 \mathrm{pF}$.

Capacitor, tantalum, $68 \mu \mathrm{F}, 15 \mathrm{~V}$.

Capacitor, tantalum, $100 \mu \mathrm{F}, 20 \mathrm{~V}$.

Capacitor, silvered mica or ceramic

Capacitor, tantalum, $33 \mu \mathrm{F}, 10 \mathrm{~V}$.

Capacitor, silvered mica, $5 \mathrm{pF}$.

Capacitor, tantalum, $150 \mu \mathrm{F}, 15 \mathrm{~V}$.

Capacitor, tantalum, $47 \mu \mathrm{F}, 6 \mathrm{~V}$.

Diode, silicon, 1N4154.

Diode, silicon zener, 1N4730.

Diode, silicon, 1N 3731 .

Dicde, germanium, $1 \mathrm{~N} 455$.

Inductor, $10 \mu \mathrm{H}$.

Transistor, silicon, N-channel field effect, 2N4860.

Transistor, silicon N-channel field effect, 2N3819.

Transistor, silicon PNP, 2N4258.

Trarsistor, silicon NPN, 2N3511.

Transistor, silicon, PNP, 2N3645.

Transistor, silicon NPN, $2 \mathrm{~N} 3643$.

Resistor, metal film, $1 \%, 93.1 \mathrm{ohm}, 1 / 8 \mathrm{~W}$.

Resistor, composition, $5 \%, 20 \mathrm{M}, 1 / 8 \mathrm{~W}$.

Resistor, metal film, 1\%, $10 \mathrm{ohm}, 1 / 8 \mathrm{~W}$.

Resistor, composition, 5\%, $100 \mathrm{ohm}, 1 / 8 \mathrm{~W}$.

Potentiometer, 1-turn trimmer, cermet, 1K.

Potentiometer, 20-turn trimmer, cermet, $50 \mathrm{~K}$.

Resistor, composition, $5 \%, 33 \mathrm{~K}, 1 / 8 \mathrm{~W}$.

Resistor, composition, $5 \%, 2 \mathrm{~K}, 1 / \varepsilon \mathrm{W}$.

Resistor, composition, 5\%, 4. 3K, $1 / 8 \mathrm{~W}$.

Resistor, composition, 5\%, $511 \mathrm{ohm}, 1 / 8 \mathrm{~W}$.

Resistor, composition or metal film "

Resistor, composition, 5\%, 82K, $1 / 8 \mathrm{~W}$.

Resistor, composition, 5\%, 22K, $1 / 8 \mathrm{~W}$.

Resistor, metal film, 1\%, $536 \mathrm{ohm}, 1 / 8 \mathrm{~W}$.

Resistor, metal film, $1 \%, 4.87 \mathrm{~K}, 1 / \mathrm{B} \mathrm{W}$. 
ELECTRICAL PARTS LIST (cont)

Circuit

Reference

Description

$R_{18}$

Resistor, metal film, 1\%, $422 \mathrm{obm}, 1 / 8 \mathrm{~W}$.

$\mathrm{R}_{19}$

Resistor, composition, $5 \%, 4.7 \mathrm{~K}, 1 / 8 \mathrm{~W}$.

$\mathrm{R}_{20}$

Resistor, composition, 5\%, 1.6K, 1/8 W.

$R_{21}, R_{22}$

Resistor, composition, $5 \%, 1 \mathrm{~K}, 1 / 8 \mathrm{~W}$.

$\mathrm{R}_{23}, \mathrm{R}_{24}$

Resistor, composition, 5\%, $5.6 \mathrm{ohm}, 1 / 8 \mathrm{~W}$.

$\mathrm{R}_{26}$

Resistor, composition, $5 \%, 10 \mathrm{~K}, \mathrm{I} / 8 \mathrm{~W}$.

Value determined by pulse decay time desired. See table in Fig. 1. 